\title{
Synthesis and Characterization of Nanocrystalline Hydroxyapatite Gel and its Application as Scaffold Aggregation
}

\author{
Leonardo Ribeiro Rodrigues ${ }^{\mathrm{a}, \mathrm{b}, \mathrm{d}, \mathrm{d} *}$, Marcos Akira d` Ávila,
}

Fernando Jorge Mendes Monteiro ${ }^{\mathrm{c}, \mathrm{d}}$, Cecília Amélia de Carvalho Zavaglia ${ }^{\mathrm{a}, \mathrm{b}}$

\author{
${ }^{a}$ Department of Materials Engineering - DEMA, Faculty of Mechanical Engineering - FEM, \\ State University of Campinas - UNICAMP, P.O. Box 6122, CEP 13083-970, Campinas, SP, Brazil \\ ${ }^{\mathrm{b}}$ National Institute of Science and Technology in Biofabrication - INCT BIOFABRIS, Campinas, SP, Brazil \\ 'Instituto de Engenharia Biomédica - INEB, CEP 4150-180, Porto, Portugal \\ ${ }^{\mathrm{d} D e p a r t a m e n t o ~ d e ~ E n g e n h a r i a ~ M e t a l u ́ r g i c a ~ e ~ M a t e r i a i s, ~ F a c u l d a d e ~ d e ~ E n g e n h a r i a ~-~ F E, ~}$ \\ Universidade do Porto - UP, CEP 4200-465, Porto, Portugal
}

Received: February 16, 2011; Revised: July 13, 2012

\begin{abstract}
The sol-gel process is a technique used to synthesize materials from colloidal suspensions and, therefore, is suitable for preparing materials in the nanoscale. In this work hydroxyapatite was used due to its known properties in tissue engineering. Hydroxyapatite $\mathrm{Ca}_{10}\left(\mathrm{PO}_{4}\right)_{6}(\mathrm{OH})_{2}$ is a bioactive ceramic which is found in the mineral phase of bone tissue and is known for its great potential in tissue engineering applications. For this reason, this material can be applied as particle aggregates on ceramic slurry, coating or film on materials with a poorer biological response than hydroxyapatite. In this work, hydroxyapatite gel was obtained by the sol-gel process and applied as nanoparticle aggregation in the mixture of hydroxyapatite and tricalcium phosphate to form a ceramic slurry. This process is the polymer foam replication technique used to produce scaffolds, which are used in tissue engineering. For HA gel characterization it was used enviromental scanning electron microscopy (ESEM), transmission electron microscopy (TEM), electron energy loss spectroscopy (EELS), scanning electron microscopy (SEM), $\mathrm{X}$-ray diffraction (XRD) and X-ray fluorescence (XRF). The crystallite size was calculated from XRD data using the Scherrer equation. The nanoparticles size before firing was approximately $5 \mathrm{~nm}$. The crystallite size calculated after calcination was approximately $63 \mathrm{~nm}$. The EELS results showed that calcium phosphate was obtained before firing. After HA gel calcination at $500{ }^{\circ} \mathrm{C}$ the XRD results showed hydroxyapatite with a small content of beta-TCP. The scaffolds obtained by polymer foam replication technique showed a morphology with adequate porosity for tissue engineering.
\end{abstract}

Keywords: nanoparticles, thin film, hydroxyapatite, scaffolds

\section{Introduction}

Hydroxyapatite (HA) is a bioceramic material usually used in tissue engineering as bone substitute. For this application, HA is typically used in the form of powder or as scaffolds. In the latter case, HA should present a three-dimensional structure with interconnected pores, which guarantees desired similarities with bone tissue, besides being bioactive ${ }^{1}$.

Hydroxyapatite has been widely studied for its application as biomaterial. Moreover, recent efforts in the development of nanostructured hydroxyapatite materials have increased its applicability range. For example, calcium phosphate ceramic composites, such as hydroxyapatite/ tricalcium phosphate (TCP), have been synthesized in such a way that the appropriate amounts of TCP and HA in the composite ensures the balance between the absorption and the formation processes of new tissue ${ }^{2}$.

In order to prepare nanostructured HA, different methods of synthesis can be used such as precipitation, sol-gel, microemulsions, sucrose-based route, among others.

*e-mail: leonardolabiomec@hotmail.com
The sol-gel process can be defined as the conversion of a precursor solution (the sol, which is a colloidal suspension of solid particles dispersed in a liquid) into an inorganic solid via inorganic polymerization reactions induced by water. Usually, the precursor is a organic metallic compound such as alkoxides or an inorganic metal salt (for example: nitrate) ${ }^{3}$. This method can be performed by two different routes: Colloidal metal alkoxide ${ }^{4,5}$ and polymeric ${ }^{6}$.

Colloidal metal alkoxide (or metal salt) route: The solvent can be alcohol or water and the resulting products are colloids in aqueous medium. Agglomerated powder may be formed after firing, which can be prevented by particle repulsion. This is the route adopted in this work.

Polymeric route: The solvent can be ethanol and the gel is formed by the condensation of small-sized particles. Amorphous structures can be formed, creating microporous systems.

In this work, the sol-gel process was used in order to produce homogeneous ceramic particles. This allowed the use of common reagents, besides being a relatively simple synthesis process. 
The sol-gel method ${ }^{7,8}$ is used for the synthesis of powders, monoliths and thin films is based on the hydrolysis and polymerization (or condensation) of alkoxide molecular precursors. An advantage of the process is that they are synthetic and able to generate solutions of high purity.

Furthermore, the sol-gel process involves the use of liquid reagents with low viscosity and therefore good homogenization of the solution can be achieved in a short time.

Metal alkoxides are members of the family of metallorganic compounds, which have organic ligands that have bound to metal atoms. The ease of reaction between the metal alkoxides and water is the main property of these chemical compounds that are of direct interest in sol-gel process.

The production of the gel is divided into two stages: hydrolysis and condensation.

Hydrolysis is the main chemical reaction that leads to the transformation of precursor to final products (oxides). A variety of physical and chemical factors such as temperature, $\mathrm{pH}$ and concentration of chemical reagents, influence the polymerization process and, consequently, the properties of the oxides.

When it is required the synthesis of large quantities of material, water is preferred than ethanol, because required amount of the water and the cost are lower.

The nanostructures (scaffolds) are based on bioinspired design by manipulating and assembling of molecules and atoms forming the natural tissue. The scaffolds are formed by nanoparticles that are known for their high reactivity in the medium due to high surface area, consequently the nanoparticle assists in the formation of natural tissue. The large surface area of a nanoparticle often leads to distinct values of reactivity, mechanical, chemical and biological properties in vitro and in vivo when compared to micro and macroscopic particles ${ }^{9}$. Agglomeration of small particles is due to Van der Waals forces, this usually occurs in order to reduce the total surface energy. Van der Waals forces are weak, and it extends over a few nanometers. To reduce the Van der Waals interactions, repulsive forces must be present, which can be accomplished such as by electrostatic repulsion or steric hindrance.

When a hydroxyapatite gel layer is applied on the surface of a material (for example, a prosthesis), the dispersed nanoparticles adhere to the surface and this fact improves the contact of the prosthesis with the natural tissue, because the smaller size of the particles increases the surface area of the prosthesis. The larger region of interaction between materials improves the cell growth process.

The small size of nanoparticles facilitates the coating of complex surfaces when using, for example, the wet sponge technique.

The objective of this study was to characterize the hydroxyapatite gel that it is used for scaffolds coating.

\section{Material and Methods}

Hydroxyapatite gel was prepared using the water-based sol-gel method for synthesis. The reagents used was phosphoric acid $85 \%$ aqueous solution (LAFAN), calcium nitrate tetrahydrate (99\% purity, Synth) and water (purified by reverse osmosis $)^{10-12}$. The molar ratio $\mathrm{Ca} / \mathrm{P}$ was 1.67 .
In order to produce hydroxyapatite with $\mathrm{Ca} / \mathrm{P}$ molar ratio $=1.67$, for each $10 \mathrm{~mol}$ of calcium, $6 \mathrm{~mol}$ of phosphorous were used. The solvent was distilled water $\left(\mathrm{H}_{2} \mathrm{O}\right)^{13-15}$.

A commercial Hydroxyapatite - HA: Hidroxiapatita Fluidinova nanoXIM-HAp202 product 50120208 was used.

In order to produce tricalcium phosphate with $\mathrm{Ca} / \mathrm{P}$ molar ratio $=1.5$, for each $3 \mathrm{~mol}$ of calcium, $2 \mathrm{~mol}$ of phosphorous were used. The solvent was distilled water $\left(\mathrm{H}_{2} \mathrm{O}\right)^{16,17}$.

A commercial Tricalcium Phosphate - TCP: Fluidinova nanoXIM-TCP202 product 50220208 was also used.

The polymer foam replication technique was applied with ceramic slurry ( $2 \mathrm{~g}$ of HA, $2 \mathrm{~g}$ of TCP and 2 mL HA gel).

First test (commercial HA/TCP with HA gel): the sponge was submitted at a temperature of calcination of 725 , with heating from $25^{\circ} \mathrm{C}$ to $500{ }^{\circ} \mathrm{C}$, and kept in $500{ }^{\circ} \mathrm{C}$ for 3 hours in order to eliminate the sponge. After this, the sponge is heated at $725^{\circ} \mathrm{C}$ to finish the process.

Second test (synthesized HA/TCP with HA gel): the temperature of sinterization was $1330{ }^{\circ} \mathrm{C}$ with heating temperature from $25^{\circ} \mathrm{C}$ to $500{ }^{\circ} \mathrm{C}$, and kept in $500{ }^{\circ} \mathrm{C}$ for 3 hours in order to eliminate the sponge. After this, the next step was to increase the temperature up to 1330 to finish the process.

The sol-gel reaction is the transformation of the molecular precursor into a highly crosslinked solid and the process to obtain the gel is shown in Figure 1.

The process starts with (i) mixing two principal solution to form the sol; (ii) aging of the sol; (iii) drying the sol until the formation of a high viscosity gel, (iv) calcinating at $500{ }^{\circ} \mathrm{C}$ with heating rate of $3{ }^{\circ} \mathrm{C}$ per minute. Finally the powders were homogenized in agate mortar to eliminate possible agglomerates of nanoparticles (Figure 1).

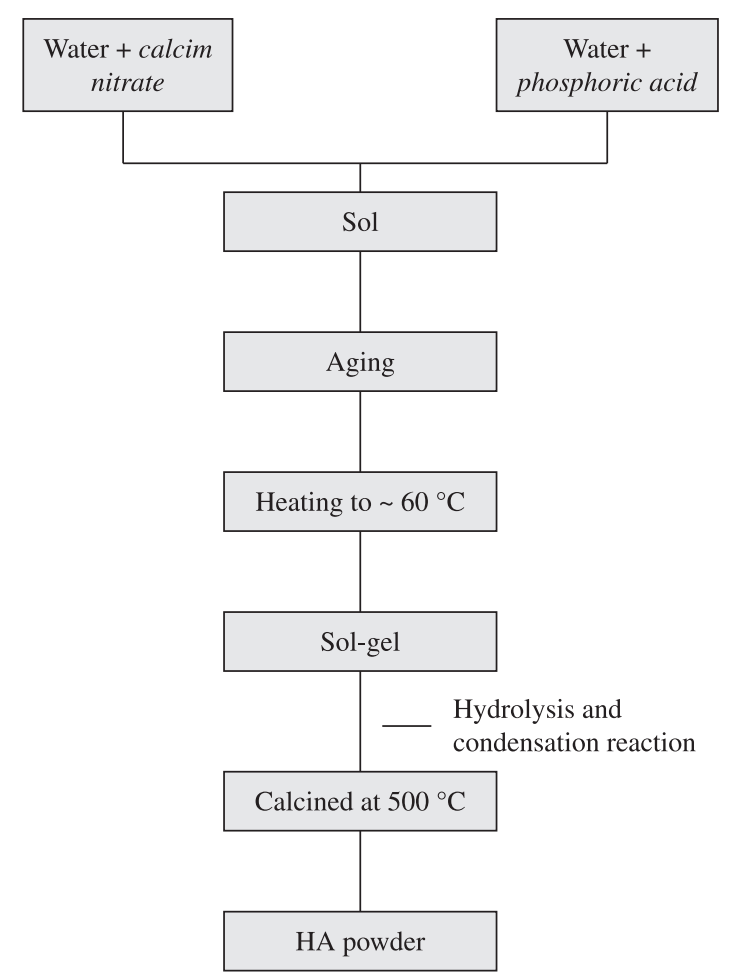

Figure 1. Diagram of sol-gel process. 
In this work the X-ray diffraction data were analyzed using the Scherrer equation in order to determine the average crystallite size of the sample ${ }^{18,19}$. To describe the equation " $\mathrm{t}$ " ${ }^{20}$ :

$$
\mathrm{t}=\mathrm{K} \lambda / \beta \cos \theta
$$

Where $\beta$ is the line width of the pure diffraction profile resulting from small crystallite size, $\lambda$ is the $\mathrm{X}$-ray wavelength, and $\theta$ is the diffraction angle. $\mathrm{K}$ is the constant approximately equal to unity and related to crystallite shape. The Scherrer constant depends on how the width is determined, the shape of the crystal, and the size distribution. The most common values for K is 0.94 for FWHM (full width at half maximum) of spherical crystals with cubic symmetry. The parameter $\beta$ was corrected by ${ }^{20}$ :

$\beta=\beta_{\text {exp }}^{2}-\beta_{\text {int }}^{2}$

Where $\beta_{\text {exp }}$ is the diffraction line width and $\beta_{\text {inst }}$ is the default width. The pattern is usually a single crystal with known crystallite size $\left(\mathrm{Si}\right.$ or $\left.\mathrm{Al}_{2} \mathrm{O}_{3}\right)$. The parameters of single crystal used were $\omega=0.06784$ and $2 \theta=28.34989^{\circ}$. For this calculation it is considered that the X-ray diffraction peak can be described as a Gaussian distribution.

ESEM (environmental scanning electron microscopy) is used in the analysis of non-metallic surfaces because of accumulation of electric charges, and allows the evaluation of viscous liquids, gels, biological samples, among others ${ }^{21}$. This type of electron microscope neutralizes the negative charge on the sample surface when the beam interacts with the gas. The type of gas can be varied when needed. In this type of microscopy, the coating is unnecessary.

ESEM provides new tools to examine the dynamic behavior of various materials under different conditions ${ }^{22}$. The equipment used was FEI Quanta model 400 FEG ESEM with secondary electron detector to visualize the gel structure and morphology of nanoparticles.

The equipment used for nanoparticle analysis before calcination at $500{ }^{\circ} \mathrm{C}$ was the transmission electron microscope (Zeiss model CEM-902) with EELS analyzer, located at IQ-UNICAMP.

The samples were analyzed using a scanning electron microscope provided with a field emission gun, SEM-FEG, (JEOL JSM 6330F). In this case the samples were coated with carbon to visualize their morphology and particle size.

Samples' crystalline phases and crystallite size were determined by X-ray powder diffraction (XRD) using a Rigaku DMAX2200 diffractometer with $\mathrm{Cu}-\mathrm{K} \alpha$ radiation $(\lambda=1.5406 \AA)$ and Ni filter. The diffractograms were obtained with velocity of $0.01^{\circ} \mathrm{s}^{-1}$ at a $2 \theta$ range varying from $20^{\circ}$ to $37^{\circ}$.

Impurity quantities were determined using a X-Ray Fluorescence (XRF) Rigaku RIX-3100 spectrometer. The samples were conformed into $25 \mathrm{~mm}$ disks and analyzed by a semi-quantitative routine.

The Nanoparticle Tracking Analysis (NTA) instrument (NanoSight NTA 2.0 model LM20) comprise of a scientific camera, microscope and a sample-viewing unit and are used in conjunction with a computer control unit, which runs the NTA software. The equipment uses a $638 \mathrm{~nm}$ red laser diode to illuminate particles in liquid suspension, which are held within the unit. NTA is used to analyze videos captured by the instrument, giving a particle size distribution and particle count.
The software identifies and tracks individual nanoparticles which are moving with Brownian motion and relates the movement to a particle size. This technique analyzes particles in liquids from 10 to $1000 \mathrm{~nm}$ (depending on material).

\section{Results and Discussion}

\subsection{Nanoparticle analysis}

Because of the gel struture, there were no particles moving under Brownian motion. After dilution (about 500 times) in pure water (18 $\mathrm{M} \mathrm{Ohm})$ the results obtained are shown in Figure 2. The system was polydispersed and all particles were drifting (might be due to the destruction of the gel structure).

Figure 2 shows particle agglomerates of about $150 \mathrm{~nm}$. These particle agglomerations also are shown in Figure 3 obtained by ESEM.

\subsection{Environmental scanning electron microscopy and scanning electron microscopy}

In Figure $3 \mathrm{a}$ it is possible to verify the gel morphology with porous structure, obtained by ESEM. In this sample, coating was not made in order to avoid hiding the real size of particles.

In Figure $3 b$ it is possible to verify the gel and nanoparticles. The gel isolates the nanoparticles, and according with Figure $3 \mathrm{a}, \mathrm{b}$, it can also be observed that the nanoparticles are spherical. Due to the structure of the gel, the image resolution was not perfect, since the sample was coated by plasma sputter coater in order to improve the conduction of electrons in the sample. By comparison with the scale it can be observed particles with size around $100 \mathrm{~nm}$.

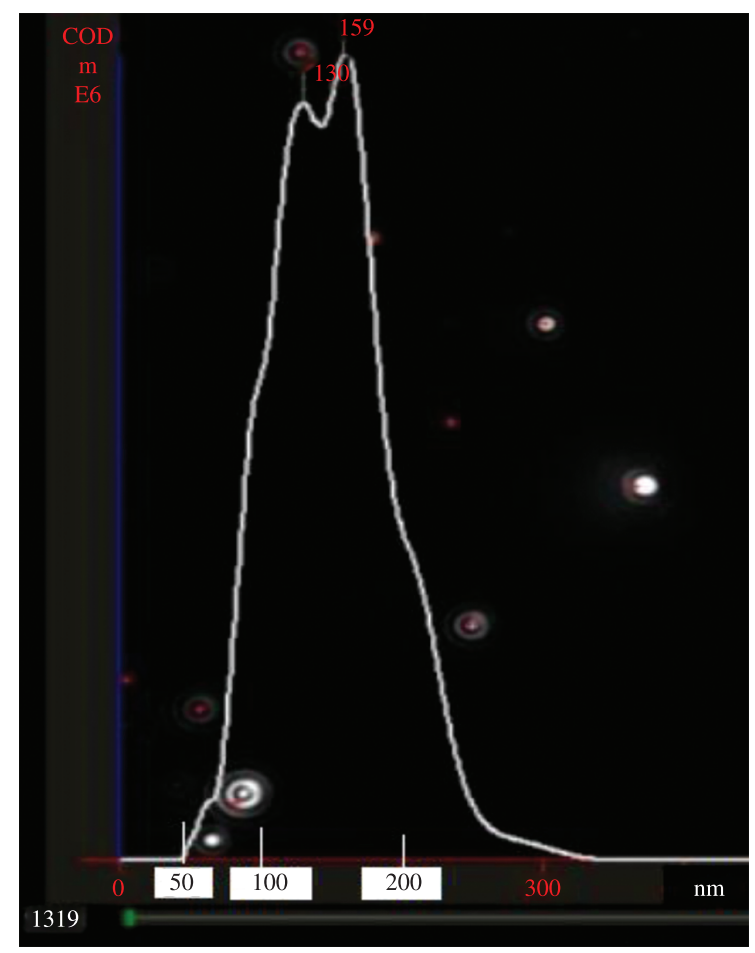

Figure 2. Nanoparticle analysis result (Nanosight). The particle size agglomerates is about $150 \mathrm{~nm}$. 


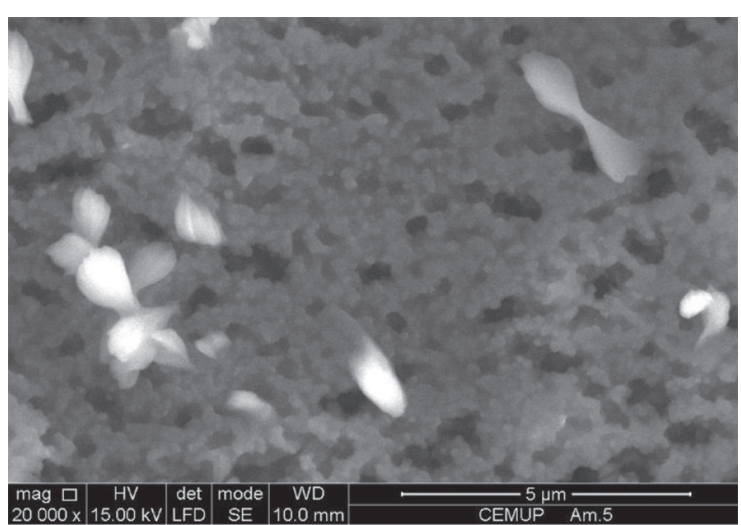

(a)

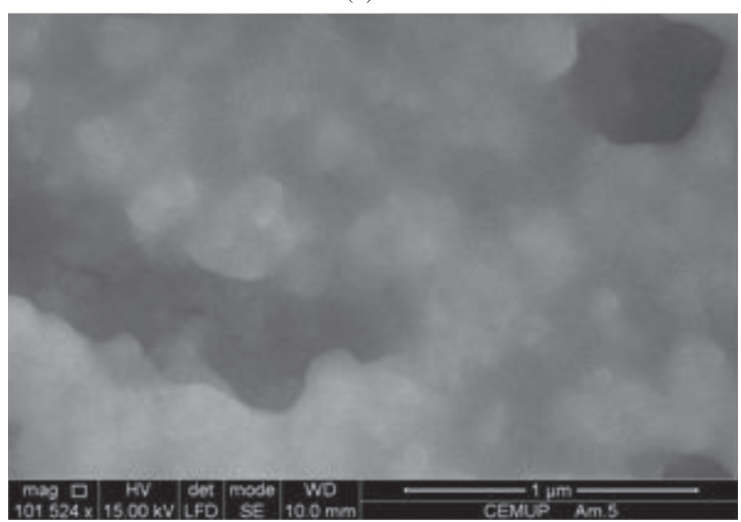

(b)

Figure 3. (FEG ESEM) Hydroxyapatite gel before calcination. (a) Overall dispersion of particles in the gel and some pores. (b) Particles dispersed in detail.

The hydrolysis during the heating process leads a dispersion of colloidal particles in a condensed gel with an interconnected and porous network. This step of the process is called the sol-gel transition and is shown in Figure $3 b$. The results show strong similarities with the theory of the structural glass transition ${ }^{23}$. The gelling solution at the sol-gel transition is a unique state of matter that is neither liquid nor solid, but rather is in transition between these states $^{24}$.

The resulting structure after the gel formation and shown in the ESEM image (Figure 3 ) is similar with the theoretical images obtained by colloidal route 25,26 .

When the gel is dried under ambient condition a solid material called xerogel is formed. This type of structure normally retains high porosity and large surface area and their pores are small, usually in the nanoscale ${ }^{27}$.

In Figure 4a, it is possible visualize the morphology of agglomerates and the material structure. In the detail it can be seen a nanoparticle aggregate with approximately $111 \mathrm{~nm}$.

Figure $4 \mathrm{~b}$ shows images of nanoparticles with size less than $50 \mathrm{~nm}$. It was thought that the particles that is observed in Figure $4 \mathrm{~b}$ was the gold coating, but the gold particles have a size of about $5 \mathrm{~nm}$, which is 10 times smaller than the particles shown in Figure $4 b^{28}$.

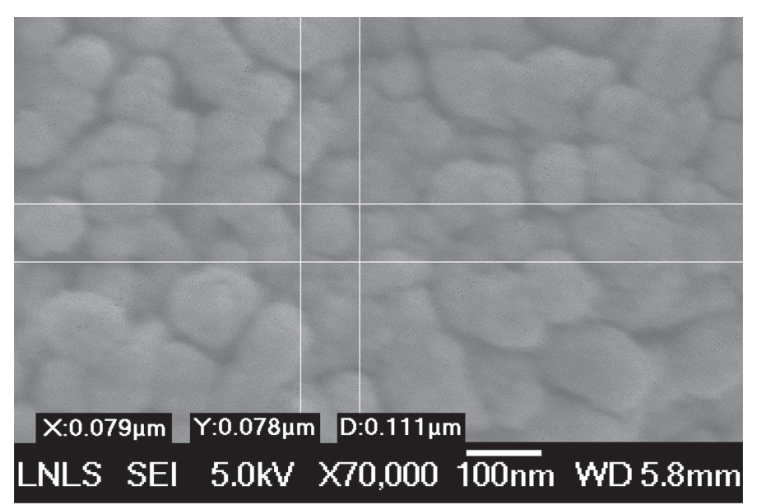

(a)

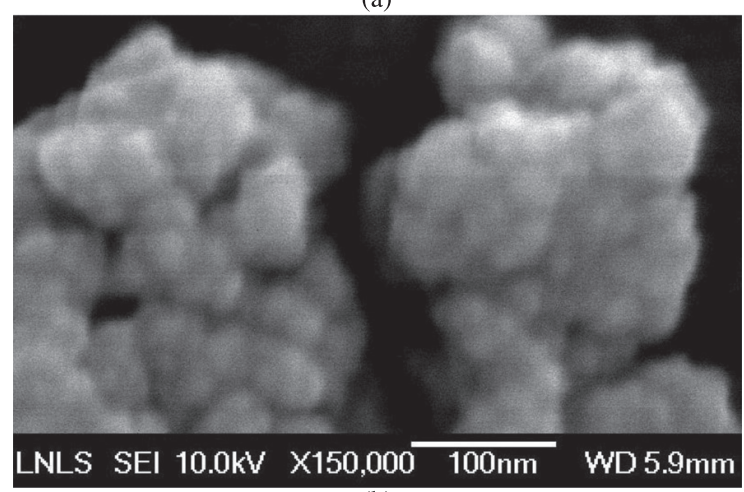

(b)

Figure 4. (a) Morphology of the particle aggregates and the cluster size of particles $\left(500{ }^{\circ} \mathrm{C}\right)$. (b) Particles agglomerates (SEM-FEG).

\subsection{TEM and EELS}

Figure 5 shows dispersed nanoparticles with sizes smaller than $5 \mathrm{~nm}$, but it can also be seen nanocrystals with approximately $20 \mathrm{~nm}$ in diameter.

We believed that when the solution becomes more concentrated and viscous, the nanoparticles of $5 \mathrm{~nm}$ are aggregated, forming larger crystals as shown in some crystals in this image. After calcination, the size of nanoparticles increased as shown in Figure 4, with nanoparticles between $80 \mathrm{~nm}$ to $100 \mathrm{~nm}$.

Excitation counts of $\mathrm{Ca} \mathrm{L}_{3,2}$-edge (Figure 5) with variation of energy loss was found to be between of 340-360 eV ${ }^{29}$. According to the EELS atlas, calcium (Ca) has the $\mathrm{L}_{2,3}$-edges and have a loss of energy $346.4 \mathrm{eV}$.

\subsection{XRD - X-ray diffraction}

Figure 6a shows the XRD of hydroxyapatite gel calcined at $500{ }^{\circ} \mathrm{C}$ for 4 hours. This sample shows the major peak of hydroxyapatite in $31.6^{\circ}$ that corresponds to hydroxyapatite (211) plane ${ }^{30}$, also between $30^{\circ}$ and $31^{\circ}$ there is a peak with low intensity of beta-tricalcium phosphate phase.

The parameters used in Scherrer equation were obtained and used to calculate a crystallite size of $63 \mathrm{~nm}$. This value analyzing was obtained by the main diffraction peak (Figure 6b), which was in a diffraction angle $2 \theta$ of $31.56621^{\circ}$ (xc 1). The Gaussian parameter was $\omega=0.23275$ (w1). 


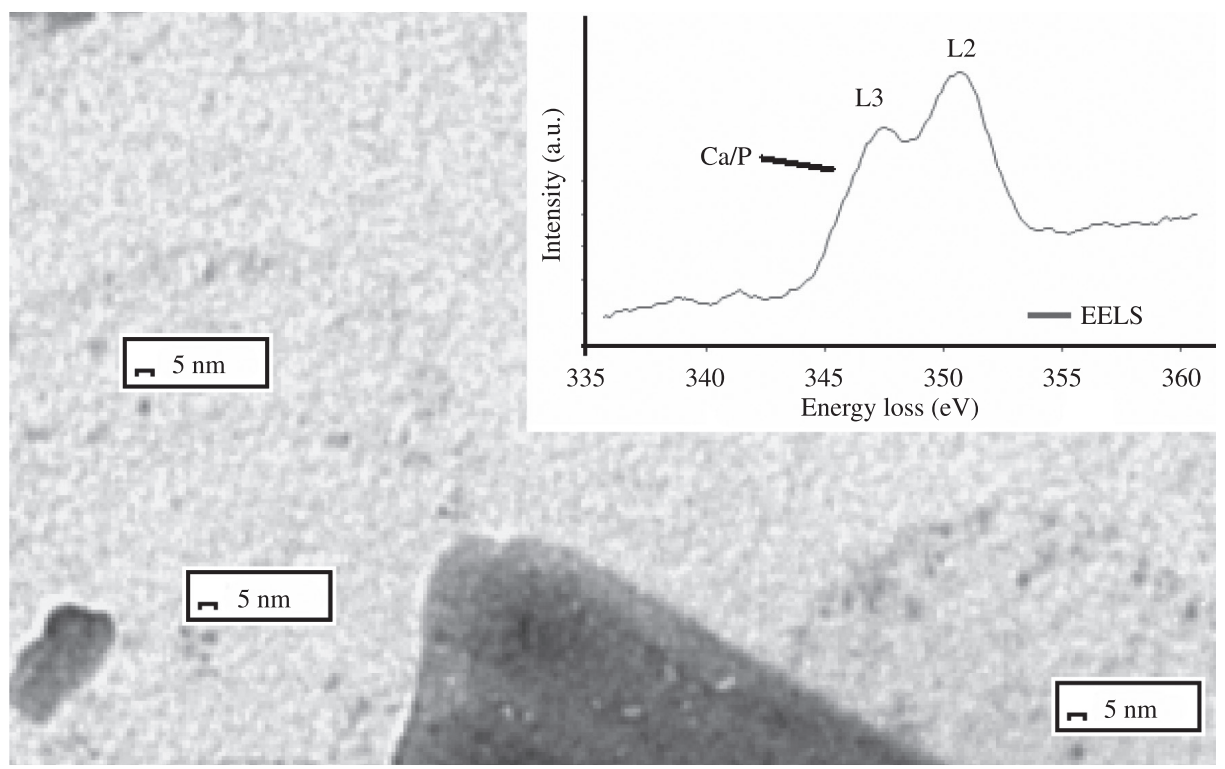

Figure 5. Results of HA gel before calcination obtained by transmission electron microscope. Detail: nanoparticles with approximately $5 \mathrm{~nm}$.

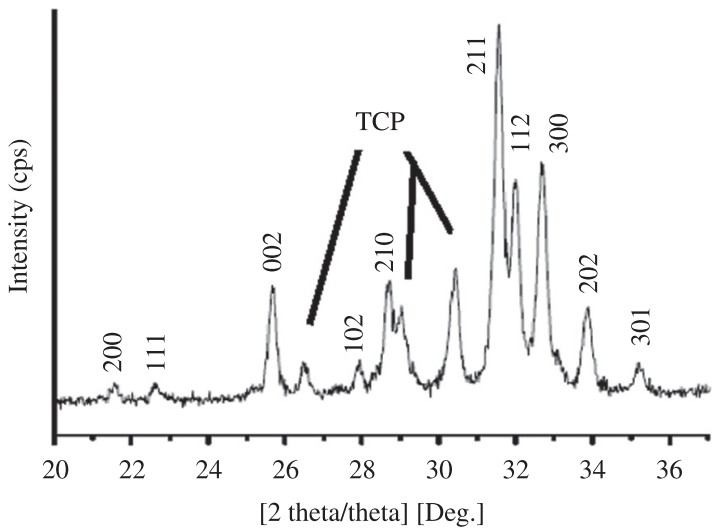

(a)

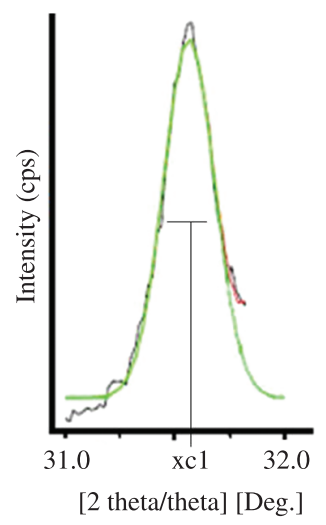

(b)

Figure 6. (a) XRD of hydroxyapatite gel calcined at $500{ }^{\circ} \mathrm{C}$ showing the HA crystal plane and some peaks of tricalcium phosphate - TCP. (b) Gaussian curve of the highest intensity peak of hydroxyapatite.

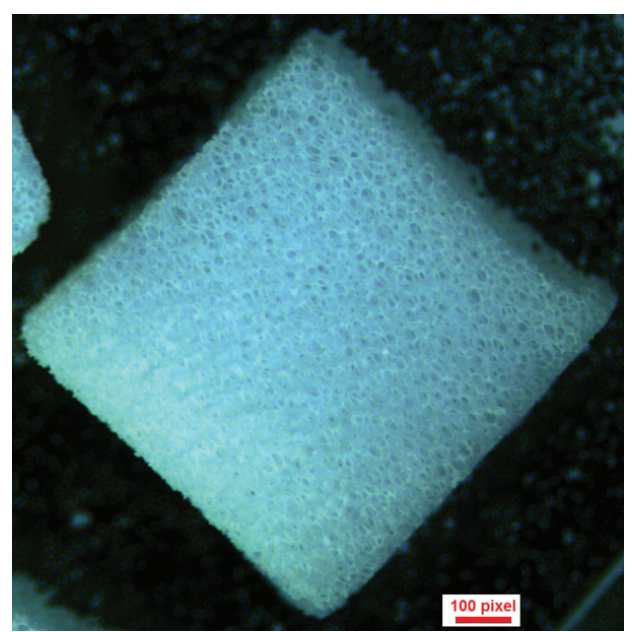

(a)

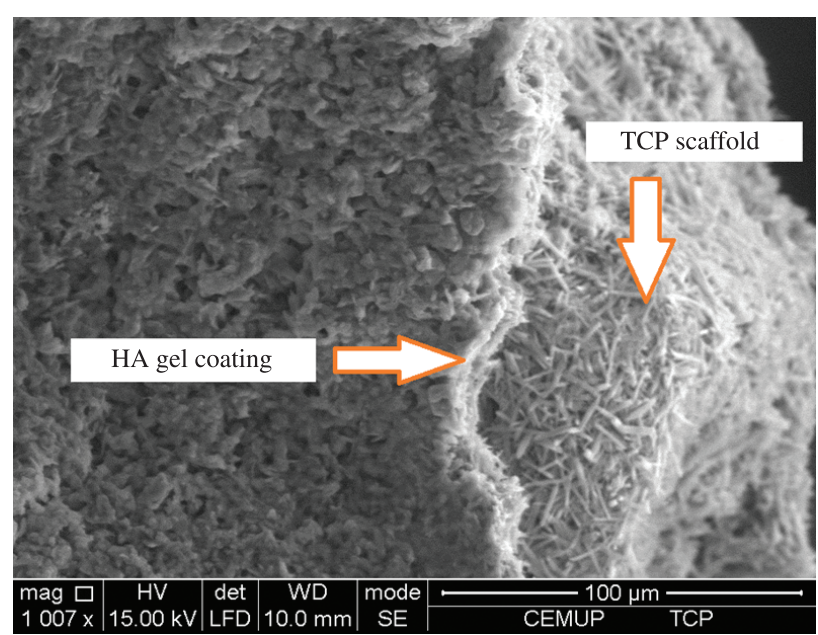

(b)

Figure 7. (a) Commercial HA/TCP ceramic sponge with HA gel coating calcined at $725^{\circ} \mathrm{C}$. (b) Detailed picture of the fracture where it is possible to verify the presence of HA gel coating. 
Table 1. Results of XRF semi-quantitative analysis (wt. (\%)).

\begin{tabular}{ccccccccc} 
& $\mathbf{S r}$ & $\mathbf{N a}$ & $\mathbf{S}$ & $\mathbf{F e}$ & $\mathbf{M g}$ & $\mathbf{S i}$ & & \\
\hline $\mathbf{5 0 0}{ }^{\circ} \mathbf{C}$ & 0.028 & 0.013 & 0.004 & 0.004 & 0.004 & 0.003 & 0.002 \\
\hline
\end{tabular}

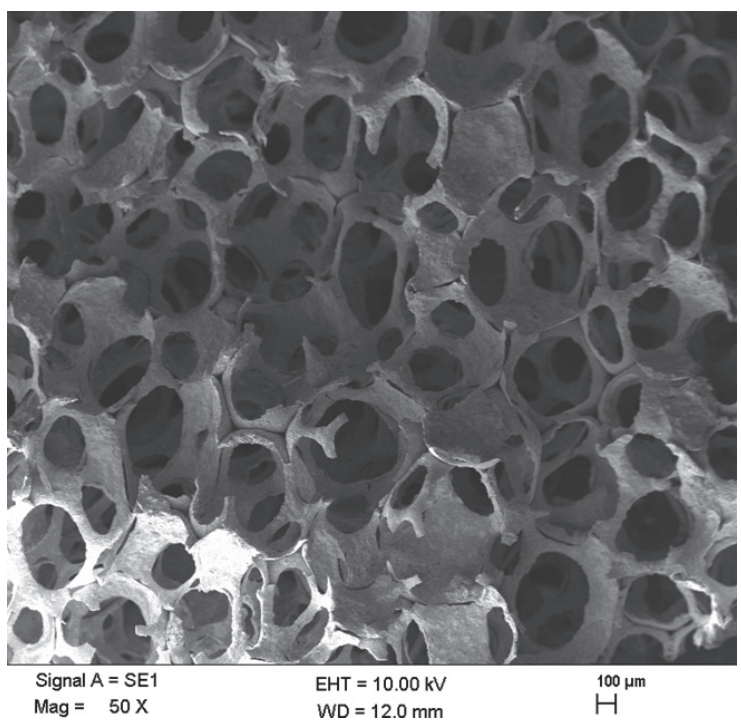

Figure 8. Synthesized HA/TCP ceramic sponge obtained by slurry ceramic, sintered at $1330^{\circ} \mathrm{C}$. Pores of scaffold.

\section{5. $X R F-X$ - ray fluorescence}

The XRF that is a semi-quantitative chemical analysis and showed that HA has low level of impurities and do not have heavy metal contamination (Table 1). This is very important because biomaterials can not have this kind of chemical elements in their structure.

\subsection{Polymer foam replication technique}

It is known that HA is a bioactive bioceramic and from the results of this work it can be seen good perspectives on the development of new orthopedic devices and tissue engineering scaffolds.

The scaffold (commercial HA/TCP) morphology calcined at $725^{\circ} \mathrm{C}$ is shown in Figure 7 a, Figure $7 \mathrm{~b}$ shows the detail of ceramic scaffold fracture, where it is possible to see the HA coating and the scaffold nanostructure.

Figure 8 shows the scaffold prepared with synthesized $\mathrm{HA} / \mathrm{TCP}$ and sintered at $1330{ }^{\circ} \mathrm{C}$ from slurry ceramic. The pores of the scaffold were found to be adequate to use in tissue engineering applications.

\section{References}

1. Zhu X, Eibl O, Berthold C, Scheideler L and GeisGerstorfer J. Structural characterization of nanocrystalline hydroxyapatite and adhesion of pre-osteoblast cells. Nanotechnology. 2006; 17:2711-2721. http://dx.doi. org/10.1088/0957-4484/17/11/001

2. Sagawa H, Itoh S, Wang W and Yamashita K. Enhanced bone bonding of the hydroxyapatite/beta-tricalcium phosphate composite by electrical polarization in rabbit long bone.

\section{Conclusions}

The gel was efficient to aggregate the particles by creating a resistant structure due to the fact that the particles have a stronger bond, because of the gel structure. This scaffold is very porous, so any increase on mechanical resistance is important.

The scaffolds obtained with commercial materials calcined at $725{ }^{\circ} \mathrm{C}$ presented nanostructure and it was possible to see the HA layer in the fracture of the ceramic sponge. Also, the sponge that was prepared using synthesized HA/TCP and sintered at $1330{ }^{\circ} \mathrm{C}$ presented interconnected pores and pores size adequate to tissue engineering applications.

Nanoparticles were already formed in the mixtures of the two solutions, but with particles size around $5 \mathrm{~nm}$ as shown in the TEM pictures. With stirring and heating, the gel became more viscous (hydrolysis and condensation), the particles tended to increase their size by agglomerating in some places, forming clusters around $150 \mathrm{~nm}$. This was observed from the results of ESEM and NTA.

With the EELS it was proved the presence of calcium indicating the formation calcium phosphate (hydroxyapatite) before calcination. With XRD it was proved the presence of hydroxyapatite crystalline phase in the diffractogram after calcination.

XRD data was used based on the main peak to perform the calculation of crystallite size, where the average value obtained was $63 \mathrm{~nm}$.

With SEM-FEG was proved that after calcination at $500^{\circ} \mathrm{C}$ the sample had it particle size agglomerates of about $100 \mathrm{~nm}$.

The XRF showed that HA presented low level of impurities and did not present heavy metal contamination.

Due to the material characteristics obtained with XRD, SEM and XRF it was suggested that the scaffolds obtained in this work might be adequate for tissue engineering applications.

\section{Acknowledgements}

The authors are thankful to CAPES and the EBW program for financial support, the Brazilian Synchrotron Light Laboratory (LNLS) for SEM-FEG facilities and the CEMUP for the ESEM analyses REEQ/1062/ CTM/2005, REDE/1512/RME/2005 funding provided by FCT-Foundation for Science and Technology - Portugal and NanoSight Ltd, for the analyses on hydroxyapatite gel.

Artificial Organs. 2010; 34(6):491-497. PMid:20456322. http:// dx.doi.org/10.1111/j.1525-1594.2009.00912.x

3. Segal DL. Sol-gel processing: Routes to oxide ceramics using colloidal dispersions of hydrous oxide and alkoxide intermediates. Journal of Non-Crystalline Solids. 1984; 63(1-2):183-191. http://dx.doi.org/10.1016/0022-3093(84)90397-1

4. Herrig $\mathrm{H}$ and Hempelmann R. A colloidal approach to nanometre-sized mixed oxide ceramic powers. Materials 
Letters. 1996; 27: 287-292. http://dx.doi.org/10.1016/0167577X(96)00011-0

5. Meyer F, Hempelmann R, Mathurb S and Veithb M. Microemulsion mediated sol-gel synthesis of nano-scaled $\mathrm{MAl}_{2} \mathrm{O}_{4}(\mathrm{M}=\mathrm{Co}, \mathrm{Ni}, \mathrm{Cu})$ spinels from single-source heterobimetallic alkoxide precursors. Journal of Materials Chemistry. 1999; 9:1755-1763. http://dx.doi.org/10.1039/ a900014c

6. Mohammadi MR and Fray DJ. Synthesis of Nanostructured and Nanoporous $\mathrm{TiO}_{2}-\mathrm{AgO}$ Mixed Oxide Derived from a Particulate Sol-Gel Route: Physical and Sensing Characteristics. Metallurgical and Materials Transactions A. 2011; 42A:2011-2481.

7. Livage J, Sanchez C, Henry M and Doeuff S. The chemistry of the sol-gel process. Solid State Ionics. 1989; 32-33(2):633-638. http://dx.doi.org/10.1016/0167-2738(89)90338-X

8. Feng W, Mu-Sen L, Yu-Peng L and Yong-Xin Q. A simple sol-gel technique for preparing hydroxyapatite nanopowders. Materials Letters. 2005; 916-919. http://dx.doi.org/10.1016/j. matlet.2004.08.041

9. Naldoni A, Minguzzi A, Vertova A, Dal Santo V, Borgesec L and Bianchi CL. Electrochemically assisted deposition on $\mathrm{TiO}_{2}$ scaffold for Tissue Engineering: an apatite bio-inspired crystallization pathway. Journal of Materials Chemistry. 2010; 21:400-407. http://dx.doi.org/10.1039/c0jm02446e

10. Santos ML, Florentino AO, Saeki MJ, Aparecida AH, Lia Fook MV and Guastaldi AC. Síntese de hidroxiapatita pelo método sol-gel utilizando precursores alternativos: nitrato de cálcio e ácido fosfórico. Eclética Química. 2005; 30(3):29-35. http:// dx.doi.org/10.1590/S0100-46702005000300004

11. Rodrigues LR. Síntese e caracterização de hidroxiapatita e titânia nanoestruturadas para a fabricação de compósitos. [Dissertação]. Campinas: Universidade Estadual de Campinas; 2008. 92 p.

12. Dean-Mo L, Troczynski T and Tseng WJ. Water-based sol-gel synthesis of hydroxyapatite: process development. Biomaterials. 2001, 22: 1721-1730. http://dx.doi.org/10.1016/ S0142-9612(00)00332-X

13. Souza EA, Duque JGS, Kubota L and Meneses CT. Synthesis and characterization of $\mathrm{NiO}$ and $\mathrm{NiFe}_{2} \mathrm{O}_{4}$ nanoparticles obtained by a sucrose-based route. Journal of physics and chemistry of solids. 2007; 68:594-599. http://dx.doi.org/10.1016/j. jpcs.2007.01.051

14. Rodrigues LR, Motisuke M and Zavaglia CAC. Synthesis of nanostructured hydroxyapatite: A comparative study between sol-gel and aqueous solution precipitation. Key Engineering Materials. 2009; 396-398:623-626. http://dx.doi.org/10.4028/ www.scientific.net/KEM.396-398.623

15. Rodriguez GNP, Rodrigues LR, Dias CGBT, D’Ávila MA and Zavaglia CAC. Electrospun Scaffolds Composed of Poly(L-lactic acid) and Hydroxyapatite. Key Engineering Materials. 2012; 493-494:872-877. http://dx.doi.org/10.4028/ www.scientific.net/KEM.493-494.872

16. Rodrigues LR, Motisuke M and Zavaglia CAC. Synthesis of b-TCP nanoparticles by sol-gel process. In: Proceedings of the 6th Latin American Congress of Artificial Organs and Biomaterials; 2010; Gramado, Rio Grande do Sul. Gramado; 2010.

17. Rodrigues LR, Dias CGBT, Monteiro FJM and Zavaglia CAC. Synthesis of Hydroxyapatite and beta Tricalcium Phosphate Using Sol-Gel Process and Analysis with FTIR. In: Proceedings of the 21st International Congress of Mechanical Engineering; 2011; Natal, Rio Grande do Norte. Natal; 2011.

18. Nag M, Basak P and Manorama SV. Low-Temperature hydrothermal synthesis of phase -pure rutile titania nanocrystals: Time temperature tuning of morphology and photocatalytic activity. Materials Research Bulletin. 2007; 42:1691-1704. http://dx.doi.org/10.1016/j.materresbull.2006.11.032

19. Cullity BD and Stock SR. Elements of X-Ray Diffraction. 3rd ed. Prentice-Hall Inc.; 2001. p. 167-171.

20. Danilchenko SN, Kukharenko OG, Moseke C, Protsenko IY, Sukhodub LF and Sulkio-Cleff B. Crystal Research and Technology. 2002; 37(11):1234-1240 http://dx.doi. org/10.1002/1521-4079(200211)37:11<1234::AIDCRAT1234>3.0.CO;2-X

21. Maronia VA, Teplitskyb $M$ and Rupichb MW. An environmental scanning electron microscope study of the $\mathrm{Ag} /$ Bi-2223 composite conductor from 25 to $840^{\circ} \mathrm{C}$. Physica C: Superconductivity. 1999; 313(3-4):169-174.

22. Wei Q, Liua Y, Wang X and Huang F. Test Method: Dynamic studies of polypropylene nonwovens in environmental scanning electron microscope. Polymer Testing. 2007; 26:2-8. http:// dx.doi.org/10.1016/j.polymertesting.2006.08.002

23. Kroon M, Wegdam GH and Sprik R. Dynamic light scattering studies on the sol-gel transition of a suspension of anisotropic colloidal particles. Physical Review E. 1996; 54(6):6541-6550. http://dx.doi.org/10.1103/PhysRevE.54.6541

24. Martin JE and Wilcoxon JP. Critical Dynamics of the Sol-Gel Transition. Physical Review Ltters. 1988; 61(3):373-376. PMid:10039314. http://dx.doi.org/10.1103/PhysRevLett.61.373

25. Hiratsuka RS, Santilli CV and Pulcinelli SH. O processo sol-gel: uma visão físico-química. Química Nova. 1995, 18(2):171-180.

26. Lima PT, Bertran CA and Thim GP. Rotas de Síntese e a homogeneidade dos precursores de mulita e cordierita. Química Nova. 1998; 21(5):608-613. http://dx.doi.org/10.1590/S010040421998000500013

27. Colomer MT and Anderson MA. High porosity silica xerogels prepared by a particulate sol-gel route: pore structure and proton conductivity. Journal of Non-Crystalline Solids. 2001; 290:93-104. http://dx.doi.org/10.1016/S0022-3093(01)00815-8

28. Zhou X, Wei Q, Sun K and Wang L. Formation of ultrafine uniform gold nanoparticles by sputtering and redeposition. Applied physics letters. 2009; 94:133107. http://dx.doi. org/10.1063/1.3111443

29. Sz-Chian L, San-Yuan C, Hsin-Yi L and Jong-Shing B. Structural characterization of nano-sized calcium deficient apatite powders. Biomaterials. 2004; 25(2):189-196. http:// dx.doi.org/10.1016/S0142-9612(03)00479-4

30. Kalita SJ and Bhatt HA. Nanocrystalline hydroxyapatite doped with magnesium and zinc: Synthesis and characterization. Materials Science and Engineering C. 2007; 27:837-848. http:// dx.doi.org/10.1016/j.msec.2006.09.036 